\title{
AGEING PROCESS OF HYDRAULIC OIL IN SINGLE-BUCKET EXCAVATORS IN ROCK MINING
}

\author{
Krzysztof Władzielczyk, Piotr Kipczak \\ AGH University of Science and Technology, Poland
}

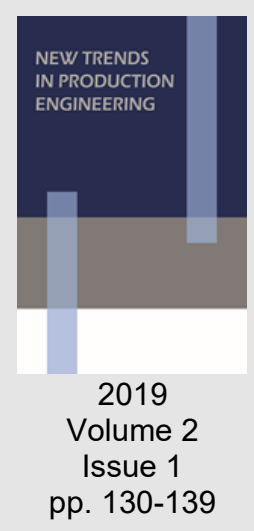

Date of submission to the Editor: 05/2019

Date of acceptance by the Editor: 07/2019

\section{INTRODUCTION}

The extraction process in Polish rock mining plants is mainly based on blasting methods with the use of explosive materials. One of the basic machines that are necessary for the implementation of the technological process of obtaining rock raw materials are single-bucket excavators. Their basic task is loading the shot rock raw material into technological dumpers or to mobile processing units (Fig. 1a). In addition, these excavators, after equipping with hydraulic hammers, break up oversize lumps created as a result of blasting, remove rock overhangs in the side of the excavation and perform other maintenance works as well as are used for selective mining of deposits in the presence of inclusions and deposits of other minerals (Fig. 1b).
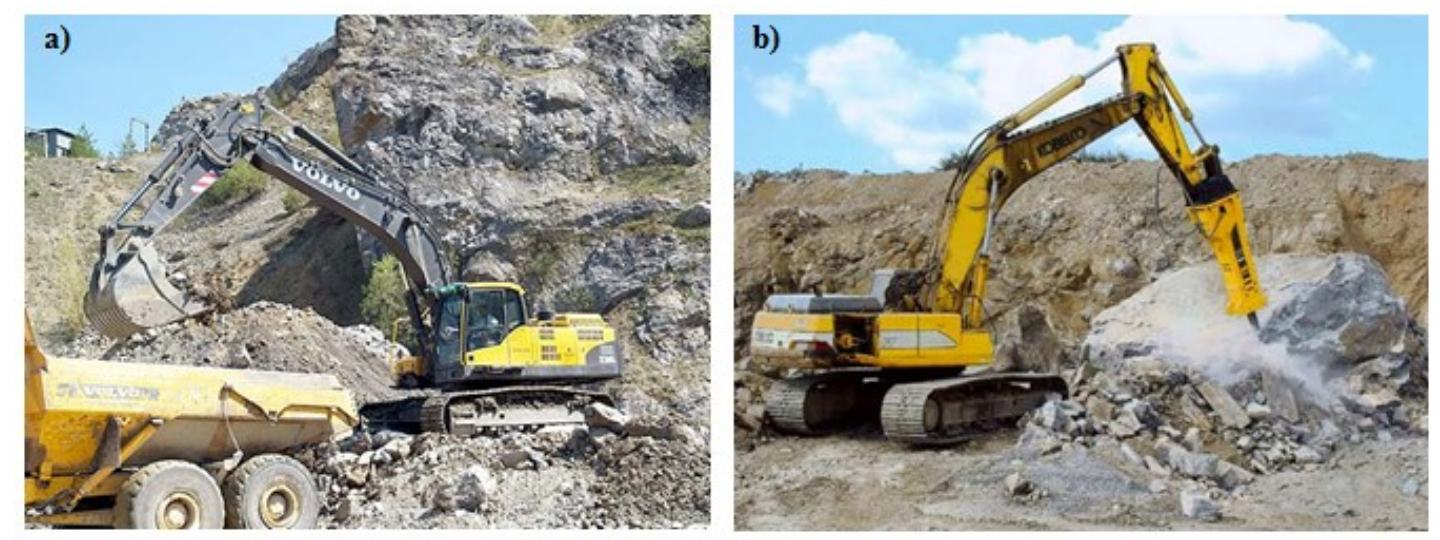

Fig. 1 Single-bucket excavators in the mines of rock raw materials carrying out: a) loading, b) shredding oversize lumps

Excavators used in Polish rock mining, regardless of their working masses, which range from approximately 21 to over $80 \mathrm{Mg}$, share several features. These include backhoe loaders on a tracked chassis. Their jib systems are usually equipped with monoboom jibs and arms adapted to the height of the mining floor, and they are adapted to the assembly of hydraulic hammers. All working functions of these excavators are carried out by means of hydraulic systems 
mounted directly on excavators. They are powered by variable capacity multipiston pump sets and a gear pump (for supplying a proportional control system). The pump sets are directly driven by diesel engines installed on the excavator body.

Ensuring proper oil parameters used in hydraulic systems of excavators determines their reliable operation and increases the durability of excavator components.

\section{CHARACTERISTICS OF THE AGEING PROCESS IN HYDRAULIC SYSTEMS OF SINGLE-BUCKET EXCAVATORS}

Currently used single-bucket excavators are equipped with hydraulic systems that operate at working pressures of up to $35 \mathrm{MPa}$. At the same time, the size of the elements which must cooperate with hydraulic oil of adequate viscosity and quality ensuring reliable functioning of these elements and thus the entire hydraulic system of the excavator, constantly decrease (it concerns both distribution and control elements as well as actuators).

Hydraulic oils used in single-bucket excavators must also have a number of other features (Dykiel 2016, Poradnik. Przemysłowe środki smarne 2003, Motyka 2018). They should have appropriate lubricating and anti-wear properties as well as corrosion inhibitors and have a high resistance to oxidation at elevated temperatures. The oil filtration capacity must be high, which is obtained by adding detergents to improve its filtration properties. The use of the highest quality oils in hydraulic systems of single-bucket excavators can significantly slow down the ageing process, but they are unable to stop it. Oils are subject to intense mechanical forcing, especially in the case of hydraulic hammers, as well as thermal and chemical ones, which gradually reduces their functional properties and, as a result, the oil must be changed.

There are three basic phenomena affecting the ageing process of hydraulic oil (Baczewski and Szczawiński 2016, Livingstone and Cavanaugh 2015), (Rensselar 2015):

- oil oxidation,

- thermal decomposition,

- contamination with solid particles.

The phenomenon of oxidation of oil is related to the reaction with oxygen contained in the air. This reaction is intensified by the elevated temperature, high pressures and the catalytic effect of metals from which the elements of the hydraulic system are made. The oil oxidation process leads to a gradual decomposition of the oil and consequently, a series of harmful substances of acidic nature are created, which affect the corrosion of oil tanks and the formation of sludge on their bottom, and eventually so-called carbon deposits. Oxidation causes changes in the colour of the oil, precipitation of solid particles that settle on the bottom of the tank and a significant increase in the acid number of the oil. Particulates can cause filter clogging. 
Thermal decomposition of oil occurs in these micro-areas of the system in which the oil temperature reaches even $1000^{\circ} \mathrm{C}$ as a result of micro-dieseling or as a result of electrical discharges caused by the generation of static electricity in the oil (Livingstone and Cavanaugh 2015, Philips and Staniewski 2016).

Oil contamination with solid particles occurs mainly in the form of products of oil ageing, wear of hydraulic system components as well as dust particles and water entering the system from the outside. Contamination particles with dimensions close to the size of the clearances occurring in the system components can cause serious damage to the hydraulic system as they lead to an increase of abrasive wear of the moving parts (sliders, mushroom valves, etc.) and seals. Particles with dimensions larger than the clearance size may in turn cause overgrowing and clogging of channels in hydraulic elements.

The ageing process of hydraulic oil during the exploitation of single-bucket excavators causes permanent irreversible changes in its properties, which may result in serious failures of hydraulic components, deterioration of the reliability of the entire hydraulic system or accelerated processes of corrosion and wear of the system components. Therefore, if deterioration of the parameters determining oil quality or loss of its properties is found, it is necessary to change the oil in the entire hydraulic system of the excavator. Available publication on the subject list various values of hydraulic oil parameters that qualify the oils to be changed. It is usually assumed that oils reach the so-called limit state, qualifying for exchange, when (Rensselar 2015, Poradnik Przemysłowe środki smarne 2003, Dykiel 2016):

- the kinematic viscosity of the oil at $40^{\circ} \mathrm{C}$ changes within $\pm 10 \%$ in relation to the viscosity of the fresh oil,

- the viscosity index of the oil is reduced by $15 \%$ in relation to the fresh oil indicator,

- the content of solid impurities in oil exceeds the value of $0.5 \mathrm{mg} / 100 \mathrm{~cm}^{3}$ of oil or it reaches the concentration and granulometric composition exceeding the purity class requirements for a given type of hydraulic system defined in the PN-ISO-4406 standard,

- the acid number increases by $0.3-0.4 \mathrm{mg} \mathrm{KOH} / \mathrm{g}$ oil or it reaches a value above $0.5 \mathrm{mg} \mathrm{KOH} / \mathrm{g}$ oil,

- the ignition temperature is reduced by $30 \%$ in relation to the ignition temperature of the fresh oil,

- the water content in the oil exceeds $0.1 \%$.

However, it should be emphasized that the given values of the oil parameters do not fully reflect the ageing process of oils. They do not take into account such factors as the content of metallic elements in the oil, which are the result of wear of hydraulic system components and may cause their serious damage.

\section{HYDRAULIC OILS USED IN SINGLE-BUCKET EXCAVATORS AND RECOMMENDED PERIODS OF THEIR USE}

Manufacturers of single-bucket excavators recommend using the same types of hydraulic oils in their hydraulic systems regardless of the planned use of 
excavators. Regardless of whether the excavator will perform standard earthworks or will be used in rock raw material plants, virtually all excavator manufacturers recommend using oils with viscosity grade VG 46 according to $\mathrm{PN}-\mathrm{ISO}$ 3448. These oils are designed to work in ambient temperatures between $-20^{\circ} \mathrm{C}$ and $+35^{\circ} \mathrm{C}$. For new excavators (with a service life of less than 10 years) it is recommended to use HV grade oils according to PN-ISO 6743-4. Oils of this class contain zinc, anti-corrosion, anti-oxidation, anti-foam and demulsifying additives. They are characterized by increased anti-wear properties thanks to the use of AW (Anti Wear) additives, anti-seizure additives (EP Extreme Pressure additives) and additives that increase the viscosity index. According to the PN-ISO 1118 standard, the viscosity index of these oils for the viscosity grade VG 46 is greater than 140.

It should be noted that in several mineral rock mines, $\mathrm{HM}$ grade oils were also used in single-bucket excavators. However, due to the lifetime of these excavators (over 15 years), they have not been included in the conducted research. Selected manufacturers of single-bucket excavators, such as Hitachi or Hyundai, offer users of excavators also the so-called oils with extended durability. The producers state that the parameters of these oils allow their use in hydraulic systems of excavators for a period of up to 5000 hours, that is 2 times as long as standard oils. These oils, however, are not used in excavators working in mines of rock raw materials, mainly due to the relatively high costs of their purchase.

The manufacturers adjust the period after which the oil in excavators working in the rock raw materials mines should be changed to the period of operation with the hydraulic hammer. For example, Hyundai recommends that the standard oil with viscosity class VG 46 and HV class should be changed after 2000 hours of excavator operation or after 600 hours of continuous operation with a hydraulic hammer. In fact, excavators in mines of rock raw materials work with a hydraulic hammer periodically, therefore, for example, company Hyundai recommends the use of special charts to determine the dates of oil change (Hyundai 2012). They enable setting the approximate date of oil change taking into account the average level of exploitation of the hydraulic hammer during the total excavator operating time. For example, oil should be changed after 1500 hours of excavator operation at $20 \%$ of the hammer operation (about 300 hours) or after 800 hours of excavator operation with $70 \%$ of the hammer utilization (560 hours).

In the rock raw materials mines, there are currently three methods for determining oil change intervals in operated excavators:

- oil changes made according to the recommendations of excavator manufacturers, which are most often carried out in the case of excavators with a low degree of use of hydraulic hammers (up to $20 \%$ of the total working time of the machine),

- oil changes resulting from the experience of users of a given excavator model, based on the time of use of hammers, but without testing oil properties, 
- oil change made as a result of periodic monitoring of the oil condition, which allows user to determine the parameters of the oil used and set the date of its change after obtaining the assumed boundary parameters.

The last method of fixing oil change intervals in excavators is used especially in machines of the latest generation, with a significant degree of use of hydraulic hammers. Its prevalence is influenced by the fact that there are a number of portable oil analyses available on the market, enabling the oil parameters to be measured directly on an excavator working in a rock raw material mine

\section{CONSTRUCTION AND MEASUREMENT CAPACITY OF THE OPCCOM PORTABLE OIL LAB}

One of the portable measuring devices that provides immediate information on the values of parameters used in the oil excavator is a portable oil analyser OPCom Portable Oil Lab, manufactured by Argo-Hytos, Fig. 2a, (Manual for portable OPCom Portable Oil Lab. 2018).

a)

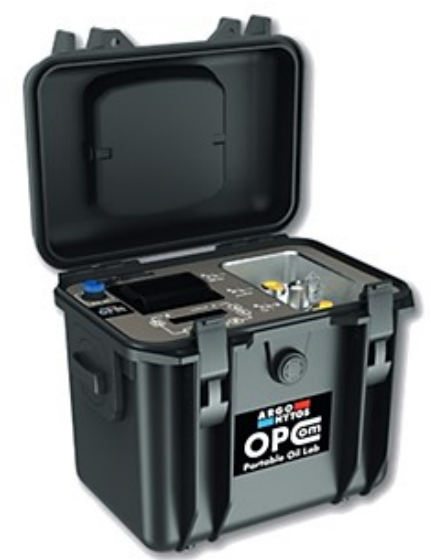

b)

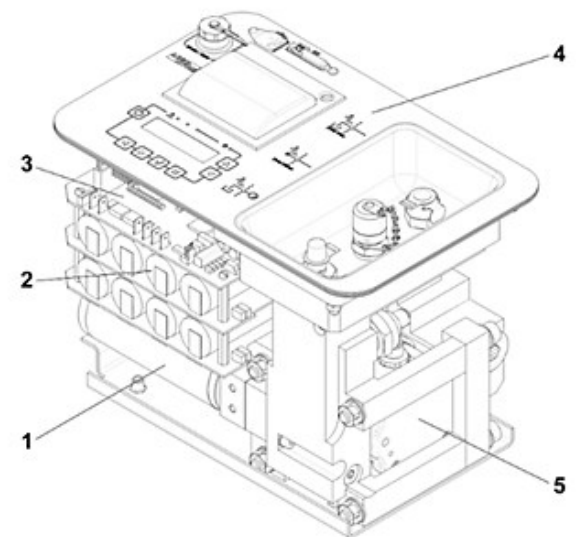

Fig. 2 OPCom Portable Oil Lab - portable oil diagnostic system: a) general view, b) individual components

The diagnostic systems allows for taking oil samples from the hydraulic system of the excavator in two ways:

- by means of a pump which is an integral part of the device (oil extraction e.g. from an oil tank),

- through the use of a minimes high-pressure connector to extract oil samples from the hydraulic system.

- The analyser, Fig. 2b, consists of the following components:

- engine and pump, which are designed to press the tested oil from the tank through the analyser to the return line,

- battery set - power source of the device in the absence of electrical network, near the place of testing,

- central unit performing measurement functions and power supply functions of the device,

- front panel with control diodes, display, buttons, connections for hydraulic hoses, SD card reader and printer, 
- a particle counter using the phenomenon of light beam scattering to measure the amount of particles in the oil,

- oil level sensor that measures the permeability, conductivity, temperature and humidity of the oil sample (not marked on Fig. 2b)

OPCom Potrable Oil Lab enables measurements of the following oil parameters:

- oil cleanliness class in compliance with three standards: PN-ISO 4406, NAS 1638, GOST 17216 and SAE AS 4095,

- the amount of solid particles in a millilitre,

- dielectric permittivity of the oil signalling whether the recommended value of the acid number was exceeded,

- specific conductivity of the tested oil allowing to determine the content of ions in the given oil,

- oil moisture,

- oil temperature,

- oil flow rate.

Obtained results of measurements of each oil sample taken can be read from the display, stored in the device memory or printed as a shortened or extended report. This portable oil analyser can work in automatic or manual mode. In automatic mode, the measurements are carried out continuously, while in the manual mode, the analyser operation stops after one test cycle. The manufacturer recommends to perform three repetitions of measurements of the given oil sample in order to obtain reliable test results in the manual mode.

\section{AIM, SCOPE AND METHODOLOGY OF THE TESTING OF OIL AGEING PROCESS IN SINGLE-BUCKET EXCAVATOR WORKING IN ROCK RAW MATERIAL MINES}

Research on the ageing process of oils used in excavators working in the rock raw materials mines, performed with the OPCom Portable Oil Lab:

- determination of the influence of working time of hydraulic hammers on the rate of the ageing process of oils used in tested excavators,

- assessment of the correctness of the intervals recommended by excavators' manufacturers to change the oil in excavators depending on the working time of the hydraulic hammer,

- possible setting of oil change dates in excavators based on the results obtained.

The diversity of the models of backhoe single-bucket excavators used in the rock raw material mines is wide, therefore prior to tests the research team selected 6 models of excavators and included them in the tests. These were Hyundai R 330LC-9A, Hyundai R 480 LC-9A (2 units), Hitachi ZX 470 LHC-5B, Caterpillar CAT 340F and Volvo ce $460 \mathrm{CL}$ excavators. The selection of the above-mentioned excavators was based on similar periods of exploitation in the rock raw materials mines, different times of hydraulic hammers and the fact that hydraulic systems of all excavators used the same type of hydraulic oil - Shell Tellus S2 VX 46. Measurements of oil parameters were carried out in the same way for all excavators selected: 
- fresh oil parameters were tested before changing the oil,

- oil condition tests were carried out every 200 hours of actual excavator operation, excavators' operators determined in detail how many hours the excavator has worked with a hydraulic hammer,

- if it is found that the class of cleanliness of the oil in the excavator is significantly exceeded, the relevant mines' departments were informed about the further exploitation of the excavator or referring the oil samples to the laboratory tests,

- the oil parameter measurement cycle was considered completed at the next oil change, and the oil was finally measured in the hydraulic tank of the excavator before the oil was changed.

The guidelines included in the PN-ISO 4406 standard were adopted to determine oil purity. The standard provides that the purity of the hydraulic oil is determined by the amounts of particles above $4 \mu \mathrm{m}, 6 \mu \mathrm{m}$ and $14 \mu \mathrm{m}$ contained in $100 \mathrm{ml}$ of oil and submission to the appropriate code number. After analysing the type of hydraulic components in the hydraulic systems of the tested excavators and the working pressure in the hydraulic system, the 18/16/14 cleanliness class was adopted as a limit value.

\section{EXAMPLES OF TEST RESULTS}

Fig. 3 and Fig. 4 show exemplary results of tests of oil contamination increase as a function of their service life in the R 330LC-9A excavator (working time with a hydraulic hammer was 295 hours) and in the ZX $470 \mathrm{LCH}-5 \mathrm{~B}$ excavator (working time with a hydraulic hammer was 385 hours).

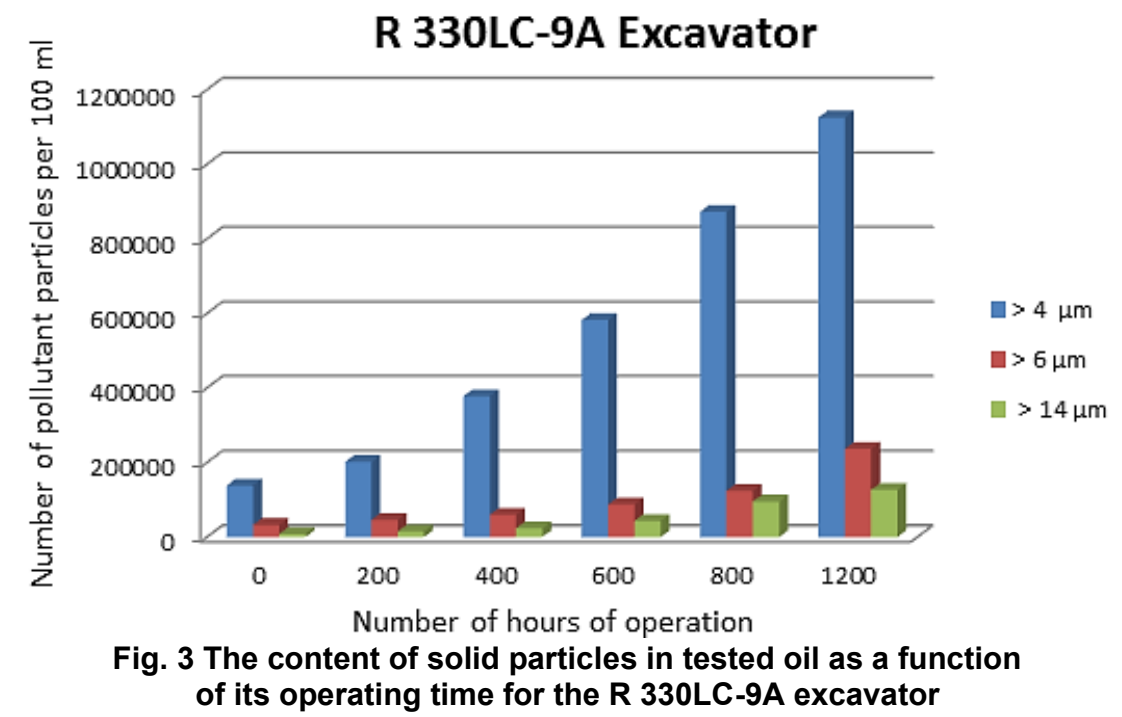

As indicated by Fig. 3 and Fig. 4, the increase in working time with a hydraulic hammer contributes to an increase in the degree of contamination of the tested oils. In the case of the R 330 LC - 9A excavator, the oil did not meet the requirements of the adopted cleanliness class after 600 hours of operation. In the case of the $\mathrm{ZX} 470 \mathrm{LCH}-5 \mathrm{~B}$ excavator, the accepted criterion of oil purity was not met already after 400 hours of oil use. 


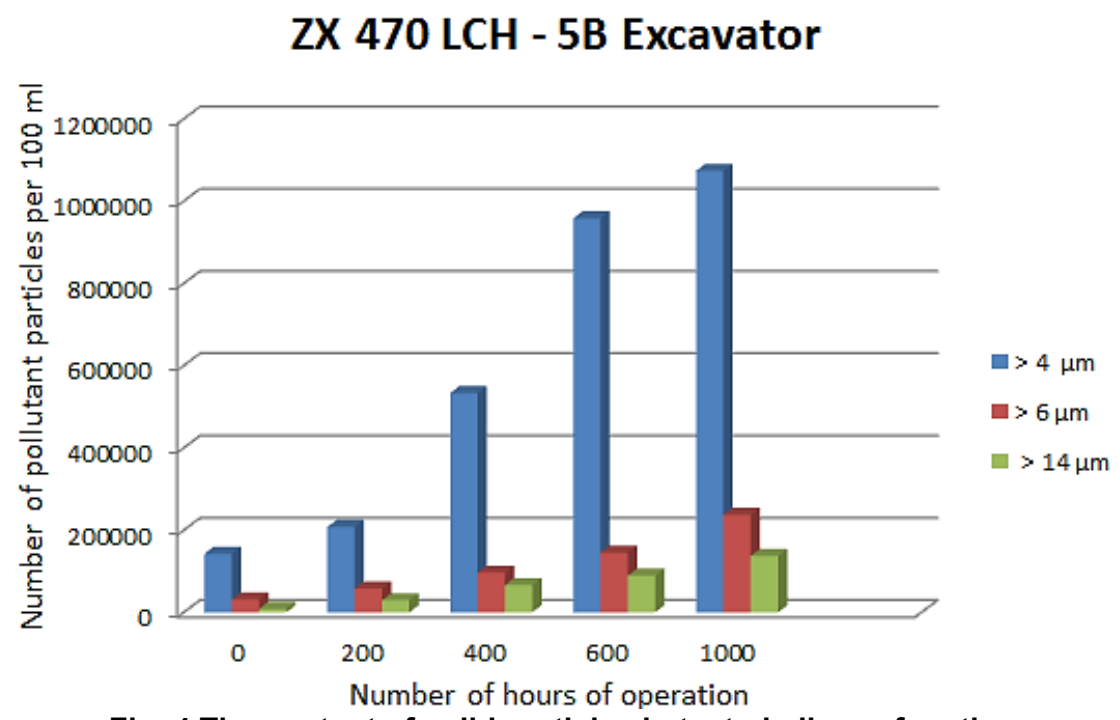

Fig. 4 The content of solid particles in tested oil as a function of its exploitation time for the ZX $470 \mathrm{LCH}-5 \mathrm{~B}$ excavator

This was influenced by a longer working life of the excavator with a hydraulic hammer in the first phase of exploitation of fresh hydraulic oil. Fig. 5 shows the time of oil exploitation in the excavators, taking into account the working time of a given excavator with a hydraulic hammer.

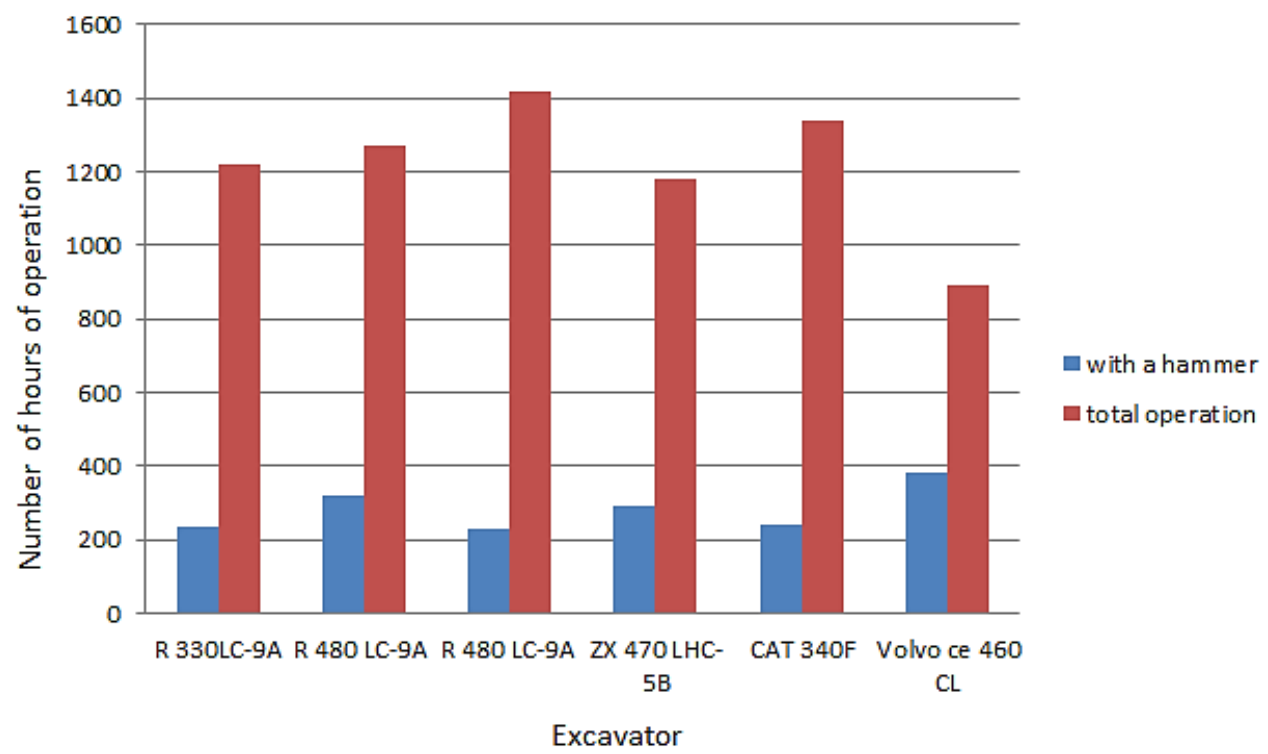

Fig. 5 Service life of olis in tested excavators including time of work with hydraulic hammers

It is clearly visible that the increase in the number of working hours of an excavator with a hydraulic hammer results in a significant reduction of the total oil service life, and thus need to change the oil earlier. This phenomenon occurred in all models of tested excavators.

\section{CONCLUSION}

Obtained results of oil ageing tests in single-bucket excavators working in the rock raw materials mines clearly indicate that the factor determining the dates of oil change in these excavators is its cleanliness class expressed by the 
concentration and granulometric composition of solid contaminants contained in the oil. The limit water content in the tested oils was not exceeded. The results of the relative permittivity tests showed that its maximum values did not exceed 2854, which means that the increase in the acid number did not exceed the recommended limit value of $0.5 \mathrm{mg} \mathrm{KOH} / \mathrm{g}$ for VG 46 oil. As expected, the working time of a given excavator model with a hydraulic hammer had the decisive influence on the rate of the oil ageing process in the tested excavators, which can be clearly seen in Figures 3, 4 and 5 . The use of hydraulic hammers significantly shortens service life of oil in excavators and causes a rapid increase in its contamination, Fig. 4.

The actual service life of fresh oils, taking into account the working time of excavators with a hydraulic hammer, differ from the values recommended by the excavator manufacturers. The obtained test results indicate that the service life of oils in these cases is shorter by $10-18 \%$ compared to the recommended values. This is confirmed both by the results obtained from the OPCom Portabe Oil Lab and the results of laboratory tests of oils made in three mines extracting rock raw materials. It is worth noting that the degree of oil contamination increased since the beginning of the use of hydraulic hammers, and after about 180 hours of operation of the excavator with the hammer the increase in the degree of pollution was very intense. Consequently, it seems necessary to monitor the cleanliness starting after 200 hours of operation with a hydraulic hammer.

The research team did not expect to obtain such results of testing the purity of fresh oils. The obtained test results indicate that it is advisable that these oils should be subjected to additional thorough filtration before being poured into the tanks and hydraulic system of excavators in order to increase the fresh oil cleanliness class. Surprisingly, the cleanliness of fresh oil depended heavily on the volume of the tank from which it was pumped to the excavator.

The requirements of the PN-ISO 4406 standard are another aspect that should be reviewed. The authors agree with the view presented in (Baczewski and Szczawiński 2016) that new requirements should be adjusted to the purity classes for currently produced oils of the highest quality classes. The requirements of the standard do not correspond to the properties of hydraulic oils of the highest quality grades and very good anti-seize, antioxidant and dispersing-detergent properties. This is evidenced, among others, by the results of cleanliness class tests of fresh, high-quality hydraulic oils used for operation in the tested single-bucket excavators working in the mines extracting rock raw materials.

\section{REFERENCES}

Baczewski, K., Szczawiński, B.(2016). Badania procesu starzenia oleju hydraulicznego podczas użytkowania. Warszawa. Arhives of Automotive Engineering.

Dykiel, S. Oleje hydrauliczne - obsługa układów hydraulicznych. (2016). FOC. Available from: http://www.fuschs-oil.pl/fileadmin/fuchs/pdf/Oleje_hydrauliczne.pdf.

Livingstone, G., Cavanaugh, G. (2015) The real reasons why hydraulic fluids fail and strategies to stop problems before they start. Tribology and Lubrication Technology. 
Philips, W., D., Staniewski, J. (2016) The origin, measurement and control of fine particles in non-aqueous hydraulic fluids and their effect on fluid and system performance. Lubrication Science.

Rensselar, J. (2015). Hydraulic fluid efficiency in construction equipment.Tribology and Lubrication Technology.

Poradnik. Przemysłowe środki smarne (2003). Total Polska Sp. z o.o.

Instrukcja obsługi i konserwacji koparek: R480LC-9. (2012). Hyundai, Polska.

Motyka, P. (2018) Wymiana olejów w układach hydraulicznych. Available from: https://hand.net.pl/wymiana-olejow-ukladach-hydraulicznych/

Instrukcja obsługi przenośnego analizatora OPCom Portable Oil Lab. (2018) Available from: $\quad$ https://www.argo-hytos.com/pl/products/sensors-measurement/portableparticle-counters/opcom-portable-oil-lab.html.

\begin{abstract}
.
The paper presents the problem of ageing processes of hydraulic oils when used in singlebucket excavators in mining of rock raw materials. Working parameters of these excavators are specific, particularly when a hydraulic hammer is mounted in place of the working bucket, therefore the course of the oil degradation process and the change times should be precisely determined as full functionality of hydraulic systems of excavators must be maintained and the wear of individual components of these systems should be reduced. Research on oil ageing processes has been carried out for excavators from various manufacturers that have operated in mines of rock raw materials of various raw material extraction quantities. The methodology adopted for testing the ageing processes of oils in excavators allowed to obtain a number of results that question the hitherto applied criteria for quality assessment of used oils in relation to the time of their actual use in hydraulic systems of excavators, as well as the time of change of such oils.
\end{abstract}

Keywords: single-bucket excavators, hydraulic oil, oil ageing process, quality testing of hydraulic oil 